\title{
UM EPISÓDIO NA EXPERIÊNCIA DE ENSINAR MATEMÁTICA
}

\section{AN EPISODE IN THE EXPERIENCE OF TEACHING MATHEMATICS}

\author{
Rosa Monteiro Paulo \\ UNESP, Universidade Estadual Paulista, rosa@feg.unesp.br \\ Rodolfo Masaichi Shintani \\ UNESP, Universidade Estadual Paulista, masaichishintani@hotmail.com
}

\section{Resumo}

Neste texto apresentamos uma atividade desenvolvida no âmbito do Programa Institucional da Bolsa de Iniciação Docente (PIBID) com alunos de segundo ano do ensino médio. $\mathrm{Na}$ atividade discutimos aspectos do conteúdo matemático funções, mais especificamente gráficos de funções trigonométricas. O objetivo foi à análise do comportamento de tais funções a partir do estudo de seu gráfico. Escolhemos o software GeoGebra e enfatizamos as funções $f(x)=\operatorname{sen}(x)$ e $g(x)=\cos (x)$ questionando os alunos sobre sua variação em termos de amplitude, período, etc. A ênfase dada a esta atividade deve-se ao fato dela possibilitar aos alunos explorar a expressão gráfica ou o aspecto visual por meio de um software, colocando os estudantes em um ambiente de aprendizagem diferente do expositivo. Percebemos que, apesar das dificuldades relativas ao uso do laboratório e da ênfase em aspectos pouco explorados em sala de aula, os alunos foram capazes de deduzir propriedades matemáticas e de dialogarem sobre conteúdos matemáticos. Discutimos, no texto, o modo pelo qual os alunos exploram o comportamento dos gráficos e o significado que atribuem às variações percebidas. Os alunos declararam que a experiência foi relevante para compreender ideias matemáticas tratadas nas aulas teóricas.

Palavras-Chave: Tecnologias Digitais; Aprendizagem Matemática, Ensino de Funções Trigonométricas.

\section{Abstract}

In this paper we will present an activity developed within the Institutional Program of the Teaching Initiation (PIBID) with second year high school students. In the activity we discuss aspects of mathematical content functions, more specifically graphs of trigonometric functions. The objective was the analysis of the behavior of such functions from the study of its graph. We choose the GeoGebra software and we emphasize the functions $f(x)=\sin (x)$ and $g(x)=\cos (x)$ questioning students about their variation in terms of amplitude and period. The emphasis given to this activity is that it enables students to explore the graphic 
expression or the visual aspect through software, placing the students in a learning environment different from the expositive one. We realized that, despite the difficulties related to the use of the laboratory and the emphasis on aspects not explored in the classroom, the students were able to deduce mathematical properties and to discuss mathematical contents. We discuss, in this text, how students explore the behavior of graphs and the meaning they attribute to perceived variations. The students stated that the experience was relevant to understand mathematical ideas treated in theoretical classes.

Keyords: Digital Technologies; Mathematical Learning, Teaching of Trigonometric Functions.

\section{Apresentando a Trama Constituída pelos Fios da Experiência Vivida}

O Programa Institucional de Bolsa de Iniciação à Docência (PIBID), em seu subprojeto Matemática que está sendo desenvolvido na Universidade Estadual Paulista "Júlio de Mesquita Filho", UNESP, campus Guaratinguetá, visa à formação de professores de Matemática para atuarem na Educação Básica.

Os bolsistas de Iniciação a Docência (ID), alunos da graduação em Licenciatura em Matemática, participam de atividades diversas desenvolvidas nas duas escolas parceiras, ambas pertencentes à rede de ensino estadual. Eles acompanham as aulas dos professores e realizam intervenções pontuais visando, por exemplo, auxiliar alunos com dificuldade de aprendizagem, contribuir em atividades de projetos ou ajudar o professor em atividades fora da sala de aula. Essa participação na escola ocorre ao menos uma vez na semana. Os bolsistas ID também elaboram e desenvolvem projetos de ensino que envolvem distintos conteúdos de Matemática nos diferentes anos da educação básica.

Essa atuação possibilita-lhes a vivência de situações de ensino nas aulas de Matemática no contexto escolar com o acompanhamento de um professor supervisor que é docente da escola e um orientador, docente da universidade. Esses projetos são elaborados conjuntamente pelos bolsistas, supervisores e orientador e seguem o Projeto Pedagógico da

Escola parceira procurando conciliar atividades inovadoras e práticas escolares já estabelecidas tendo em vista o desenvolvimento dos alunos e à aprendizagem Matemática.

O tema deste texto é inspirado em um dos projetos desenvolvidos numa das escolas parceiras. O foco das ações é o estudo de funções trigonométricas com o software Geogebra. A escolha por esse conteúdo foi motivada pelo diálogo com a professora 
responsável pela turma na qual as ações foram desenvolvidas. A turma de alunos participantes do projeto que apresentamos no texto é de segundo ano do ensino médio e o conteúdo matemático eleito para as discussões é o das funções trigonométricas da forma seno e cosseno.

O software Geogebra foi eleito para o desenvolvimento das atividades, pois, além de ser um software de uso livre e disponível no laboratório de informática da escola, entende-se que as mídias digitais no ensino de Matemática possibilitam a construção de hipóteses por parte do aluno e dá-lhe oportunidade de testá-las e validá-las (ou refutá-las) envolvendo-o num processo investigativo que caracteriza o próprio pensamento matemático. Segundo Borba (2010), a exploração possibilitada pelo software permite que os pressupostos ou hipóteses iniciais sejam explorados e, mediante a análise do que é feito, algumas generalizações podem ser construídas. Isso, segundo o que compreendemos, é essencial ao pensar matemático, pois, como afirma Ponte (2017), favorece o desenvolvimento do raciocínio dedutivo, essencial ao conhecimento matemático e possibilita o raciocínio indutivo, essencial a geração de novos conhecimentos. Além disso, o uso de tecnologia na sala de aula pode propiciar uma mudança no ambiente, tornando o aluno mais participativo $e$ responsável por sua aprendizagem de modo que, ao professor, fique a responsabilidade pela criação de oportunidades de aprendizagem.

O projeto que desenvolvemos e, neste texto, iremos apresentar e discutir teve como objetivo principal:

a) Do ponto de vista da produção de conhecimento matemático, explorar as funções seno e cosseno;

b) Do ponto de vista do desenvolvimento social, favorecer o trabalho colaborativo e a expressão do compreendido.

Para que tais objetivos pudessem ser atingidos, elaboramos atividades que seriam desenvolvidas no laboratório de informática, ambiente da escola no qual tínhamos acesso aos computadores com o software instalado. As ações iniciais visavam à apresentação do software aos alunos, já que alguns não o conheciam. Após a exploração das ferramentas do software, distribuímos, para cada dupla de alunos, fichas de atividade contendo instruções. Ou seja, as fichas encaminhavam a tarefa que o aluno deveria desenvolver. Cada tarefa continha um grupo de funções trigonométricas, sendo o grupo definido por propriedades que 
desejávamos que os alunos explorassem graficamente. Essas explorações tinham o intuito de levar os alunos a construir hipóteses sobre as variações que os gráficos sofriam mediante algumas transformações solicitadas. O trabalho em dupla incentivou o diálogo acerca do conteúdo dando-nos a conhecer o modo pelo qual os alunos o compreendiam.

\section{Explicitando o Fazer na Sala de Aula}

Para que seja possível ao leitor compreender o que foi feito com os alunos, iremos detalhar uma das tarefas propostas. Essa tarefa compunha o primeiro grupo de funções e tinha como objetivo explorar as variações de amplitude percebida pela exploração do gráfico. Para tanto, pedimos aos alunos que inserissem no software as funções do tipo " $a{ }^{*} \operatorname{sen}(x)$ ". A intenção era que os alunos concluíssem que, com $a>0$, os valores da imagem da função passariam a pertencer ao intervalo [-a, a] e que, portanto, a amplitude era dada por "a".

A exploração deu-se de modo detalhado. Ou seja, iniciamos a construção do gráfico das funções em que o valor de "a" variava gradativamente. Os alunos construíram no GeoGebra as funções $f(x)=\operatorname{sen}(x), h(x)=2 \operatorname{sen}(x)$ e $g(x)=3 \operatorname{sen}(x)$. Embora esta seja uma forma limitada para exploração, ela permite que o aluno visualize na janela de álgebra (à esquerda na tela do computador) a sentença Matemática que expressa as funções em cores correspondentes as do gráfico na janela de visualização (à direita na tela do computador).

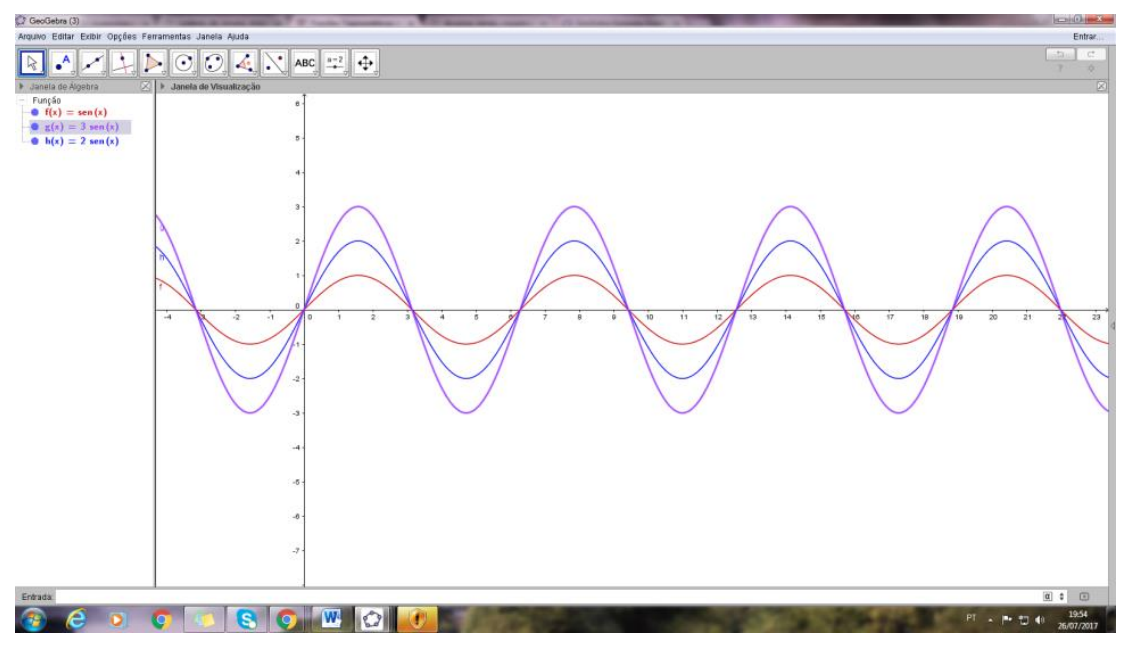

Figura 1: construção do gráfico da função $f(x)=a^{*} \operatorname{sen}(x)$ no GeoGebra Fonte: autoria própria 
Os alunos, a partir do que na tela do computador se mostrava, perceberam que quanto maior fosse o coeficiente "a", maior seria a amplitude do gráfico, embora ainda não tivessem o termo "amplitude" em seu vocabulário para falar do que estavam percebendo. $\mathrm{Na}$ figura acima trazemos uma cópia do que os alunos fizeram no software. Eles destacaram que a função em lilás (mais "alta"), que expressa $h(x)=3 \operatorname{sen}(x)$, e a função em vermelho (mais "baixa"), que expressa $f(x)=\operatorname{sen}(x)$, têm gráficos distintos. Ou seja, destacam como característica da função ela ser "mais alta" ou "mais baixa", tomando como referência da comparação o eixo x. Mas o que faz com que a curva seja "mais alta" ou "mais baixa"? Essa foi uma questão que permeou a discussão nos grupos. Fazendo variações em "a”, os alunos notaram que tal diferença era dada em decorrência da "mudança" em seus valores. No caso destacado acima para $a=1, a=2$ e $a=3$, o software mostrava-Ihes curvas distintas. Notamos que os grupos fizeram várias investigações alterando os valores de "a" para validarem sua hipótese e concluíram que, se o coeficiente da função $h(x)$ é maior que o coeficiente da função $f(x)$, então a amplitude da $h(x)$ é maior do que a de $f(x)$ - destaca-se que essa linguagem ainda não era própria aos alunos. Mas, os alunos perceberam que poderiam colocar um ponto P sobre a senóide e fazê-lo percorrer a curva observando sua projeção no eixo y. Notaram que o valor "máximo" e "mínimo" que assumiam relacionava-se com o valor de "a". Isso possibilitou explorar o sentido da imagem nesse grupo de funções.

A partir das discussões que sucedeu a exploração gráfica, foi possível definir amplitude da função seno e sugerir outras investigações envolvendo funções trigonométricas.

O modo pelo qual nos voltamos para o feito procurando analisar como os alunos se envolviam com as explorações e davam sentido às suas "descobertas", nos motivou a escrever este texto e expô-lo como possibilidade de ação na sala de aula de matemática que revela aspectos da insubordinação criativa. Isso porque, se consideramos o que afirmam Lopes e D’Ambrósio (2015, p. 2), "atrever-se a criar e ousar na ação docente decorre do desejo de promover uma aprendizagem na qual os estudantes atribuam significados ao conhecimento matemático". Vimos que nossa ação foi motivada pelo desejo de que a exploração da função trigonométrica fizesse sentido ao aluno, de tal forma que seu contato com o estudo de tais funções fosse além da repetição das definições ou reprodução de técnicas em exercícios. 
Estar com os alunos em sala de aula, acompanhando as ações do professor, propondo questões, instigando a investigação nos grupos, permitiu-nos ver a relevância de ousar para que o conteúdo matemático passe a fazer sentido ao aluno. O trabalho com o software GeoGebra mostrou-se como uma possibilidade de visualização. Isso porque, segundo o que interpretamos, as dificuldades que, no cotidiano da sala de aula, se mostrava, eram relativas à visualização. Ou seja, o aluno não era capaz de "ver" o que no quadro de lousa e giz the era explicado como variação da função, tipo de função, etc. As funções trigonométricas Ihes pareciam "algo" completamente estranho ou apenas mais um modo "esquisito" de escrever. Afinal, qual a diferença entre trabalhar com a construção gráfica de uma função do tipo $f(x)=a x^{2}+b x+c$ ou outra do tipo $g(x)=a^{*} \operatorname{sen}(x)$ ?

A base ética requerida pelas atitudes de insubordinação criativa que compreendemos nos textos de D'Ambrósio e Lopes (2015), pareceu-nos clara neste momento de indagação: qual aprendizagem é mobilizada por esse ensino? Quais oportunidades de investigação e desenvolvimento de raciocínio, exigidas num processo de produção de conhecimento, são favorecidas ao se explorar "tipos" de funções? Eticamente, a função do ensino é a aprendizagem. Ético é pensar modos de o aluno compreender o que é feito. Esse pensar, e o diálogo com o professor responsável pela turma, abriu a possibilidade de desenvolvimento de ações que questionavam a forma pela qual as funções eram ensinadas aos alunos e o potencial desse modo de ensinar para aprender.

O envolvimento dos alunos com a exploração da função sen(x) motivou outras explorações. Um grupo de funções do tipo $a^{*} \cos (x)$ foi sugerido para que os alunos explorassem graficamente. Vimos que o sentido da amplitude do gráfico da função $a^{*} \cos (x)$ não era mais um problema. Os alunos eram capazes de fazer transformações no gráfico e dizer o que percebiam com facilidade. Partimos, então, para a exploração da ideia de período nas funções trigonométricas.

Para isso retornamos a função $f(x)=\operatorname{sen}(x)$ e sugerimos que eles fizessem alterações do tipo $g(x)=\operatorname{sen}\left(b^{*} x\right)$. Incentivamos que eles variassem o valor de "b" gradativamente. Notamos que os alunos já tomavam a função $f(x)=\operatorname{sen}(x)$ como inicial para a comparação e construíam um plano de alteração do valor de "b".

Vamos considerar para a discussão neste texto, o grupo de funções $f(x)=\operatorname{sen}(x), g(x)$ $=\operatorname{sen}(2 x)$ e $h(x)=\operatorname{sen}(4 x)$, construída por um dos grupos. 


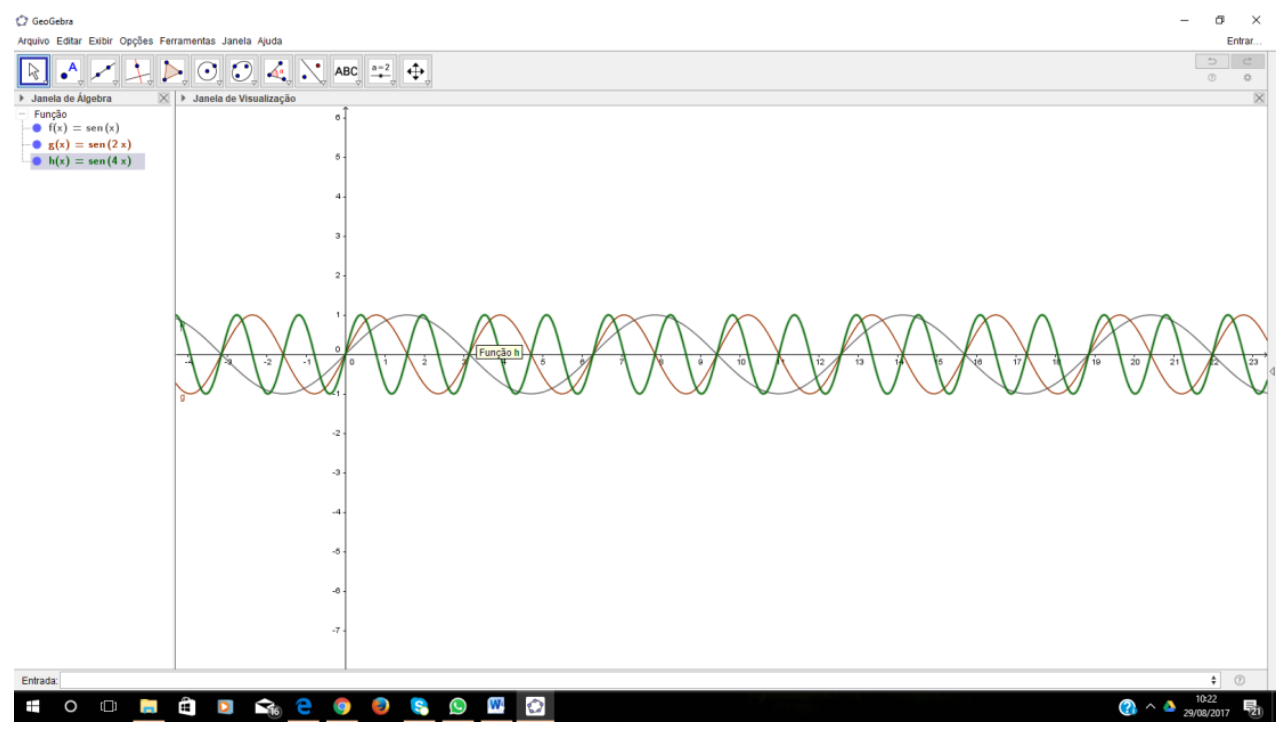

Figura 2: construção do gráfico da função $f(x)=\operatorname{sen}\left(b^{*} x\right)$ Fonte: autoria própria

O diálogo entre os alunos mostrava que eles, ao explorarem o grupo de funções do tipo $f(x)=\operatorname{sen}\left(b^{*} x\right)$, já se voltavam para as alterações que percebiam na tela do computador procurando um modo de justifica-las. Concluíram, com certa facilidade, que o valor de "b" era responsável pelo "alongamento" ou "encurtamento" da curva. Ao serem questionados eles diziam que, caso o "b" fosse um número maior que 1 a curva seria "mais curta", relativamente a função inicial $f(x)=\operatorname{sen}(x)$, e caso "b" fosse um número menor do que 1 , a curva seria "mais esticada". Para entender o sentido que os alunos estavam atribuindo às expressões "mais curta" e "mais esticada" fomos questionando-os. Vimos que a referencia que tomavam era a interseção da curva com o eixo $x$. Ou seja, considerando a origem do sistema e a função $f(x)$ $=\operatorname{sen}(\mathrm{x})$ como parâmetro, eles comparavam "onde" as curvas interceptavam o eixo $\mathrm{x}$ : antes ou depois de $f(x)$ ? Isso os fazia dizer que as curvas eram "mais curtas" ou "mais esticadas".

A partir do que eles diziam procuramos um modo de levá-los a sistematizar o compreendido. Para tanto, sugerimos, a partir da análise da construção gráfica, o preenchimento de uma tabela como a que vem a seguir, nomeando o que eles haviam destacado.

\begin{tabular}{|l|l|l|l|l|}
\hline Função & Domínio & Imagem & Amplitude & período \\
\hline $\mathrm{f}$ & $\mathrm{R}$ & {$[-1,1]$} & 1 & $2 \pi$ \\
\hline $\mathrm{g}$ & $\mathrm{R}$ & {$[-1,1]$} & 1 & $4 \pi$ \\
\hline
\end{tabular}

Quadro1: sistematização da atividade para as funções $f(x)=\operatorname{sen}(x)$ e $g(x)=\operatorname{sen}(x / 2)$

Fonte: elaborado pelo autor 
Seguindo-se as explorações, sugerimos que os grupos investigassem funções do tipo $f(x)=\operatorname{sen}(x)+c$, sempre comparativamente à função $g(x)=$ sen $(x)$. Nessa altura, os alunos já estavam bastante familiarizados com o software e integrados no grupo. O diálogo era fluido e as investigações passavam a ser coletivas. Ou seja, havia várias sugestões de como fazer o gráfico, de como alterar a aparência da tela, de como registrar o que era observado, etc.

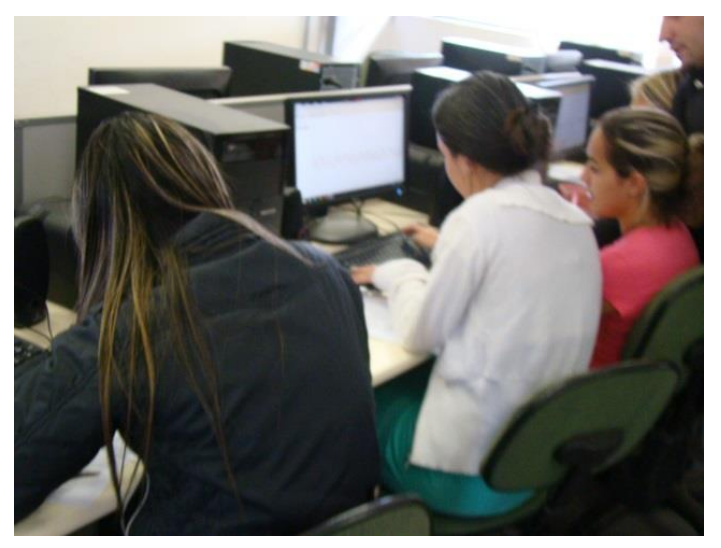

Figura 3: integração dos grupos

Fonte: Arquivo do autor

Os alunos diziam, por exemplo, que "ao somar um valor na expressão, o gráfico seria levantado" e "caso o valor de 'c' fosse negativo, haveria uma 'queda' no gráfico". A ideia era que o gráfico, em função do valor de "c", positivo ou negativo, "subia" ou "descia" relativamente à função inicial f. A transformação que ocorria no gráfico estava clara aos alunos, mas era preciso sistematizar o que observavam e nomear de modo que fossemos nos aproximando da generalidade matemática. Fizemos isso, novamente, explorando a imagem gráfica e a escrita na tabela, conforme o anterior.

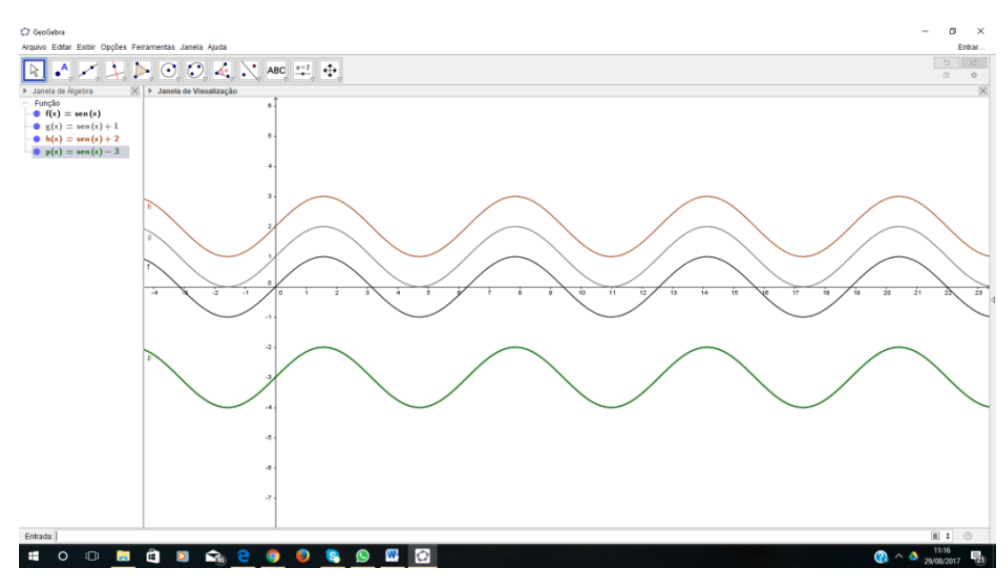

Figura 4: gráfico das funções $f(x)=\operatorname{sen}(x)+c$.

Fonte: autoria própria 
O modo pelo qual os alunos expunham a exploração feita e as conclusões que conseguiam expressar demonstrava que eles compreendiam a ideia de translação e, portanto, na exploração dessa tarefa enfatizamos a imagem da função.

\section{$\operatorname{Re}($ tomando) o Sentido da Experiência Vivida}

Embora não haja nada novo no modo aqui relatado de trabalhar as funções trigonométricas, ou nada que seja surpreendente, do ponto de vista metodológico ou mesmo do recurso utilizado (afinal, explorou-se graficamente com um software), entendemos que há um processo criativo ao se considerar a disponibilidade do aluno para aprender. Ou seja, conforme destacam D’Ambrósio e Lopes (2015), a criatividade é própria ao ser humano uma vez que o tempo todo, nas situações cotidianas, enfrentamos e resolvemos problemas. $\mathrm{Na}$ sala de aula os "problemas" são exercícios (ou tarefas) que os alunos devem fazer e que já trazem, em seu estilo ou em sua proposta, um modo próprio de ser solucionado. O maior problema (ou talvez o real problema) é "descobrir" qual é o modo para cada tipo de problema. O aluno deve ser capaz de identificar a fórmula adequada à solução do problema ou a regra que melhor se adeque a determinada situação. Mas, o melhor não seria, a exemplo do que acontece nas situações cotidianas, deixar que os alunos elegessem a forma adequada de solução?

Criar oportunidade de o aluno investigar uma situação e solucioná-la livremente, no espaço da aula, traz alguns riscos. Um deles é o próprio desânimo, já que o aluno não está habituado a procurar caminhos para a solução e, dependendo do grau de dificuldade que a tarefa Ihe impõe, ele poderá desistir de tentar solucioná-la. Porém, se o aluno não se envolve com a proposta, a aula, como um todo, pode estar fadada ao fracasso. Mas, se o aluno vê possibilidades de aprender matemática com essa abertura à investigação que lhe é dada, ele passa a investigar e tal modo que o sentido parece abrir-se para ele. Essa abertura de sentido também é necessária ao professor. Se ele vê o ensinar matemática como uma oportunidade que se dá ao aluno para buscar alternativas, fazer conjecturas, argumentar e defender perspectivas, ele se dispõe a arriscar. Isso, para nós, estava muito claro desde o início, quando fizemos a proposta de trabalho. Mas, consideramos relevante, ao final das atividades, ver o modo pelo qual os alunos compreendiam o que havia sido feito. 
Logo, ao final das explorações, pedimos aos alunos que avaliassem a atividade redigindo um pequeno parecer (texto). Conversamos sobre a proposta dizendo-Ihes que era importante que considerassem se a atividade Ihes tinha sido interessante, se auxiliara a aprendizagem dos conteúdos e outras observações que quisessem fazer. Sugerimos que eles não se identificassem para que as opiniões fossem sinceras.

Nos textos construídos os alunos disseram que a atividade contribuiu para que eles vissem a aula de Matemática de outra forma; uma forma que lhe permitia explorar exemplos, conversar e falar sobre suas dúvidas e descobertas. Declararam que se sentiram capazes de "descobrir coisas" e "escrever o que haviam descoberto".

Alguns alunos descreveram o modo pelo qual compreendiam o conteúdo: "eu gostei porque me ajudou a entender melhor o gráfico do cosseno e percebo que, quando eu uso 0 software, a visão da função é melhor do que quando eu vejo a função na lousa" (Texto do estudante A). Outros alunos focaram o modo pelo qual viram a dinâmica da proposta: "eu gostei, foi muito /.../ interessante e /.../ muito interativo /.../ poder fazer no computador, conversar e escrever o que eu via" (Texto do estudante B).

A partir do que eles escreveram nos sentimos encorajados a fazer-Ihe uma nova proposta. Sugerimos que eles escrevessem uma carta endereçada a uma pessoa qualquer que poderia ser um familiar ou um famoso que o estudante admirasse. Para tanto eles deveriam considerar que essa pessoa não conhecia Matemática e não havia participado da aula. A intenção era que, na carta, eles pudessem explicar uma função trigonométrica, destacando aspectos que consideravam essencial ao outro para aprender. Os alunos decidiram que metade da turma ficaria com a função seno e a outra metade com a função cosseno. Pedimos que o trabalho fosse individual, ou seja, cada um deles deveria escrever uma carta. Todos os alunos escreveram a carta e destacaram aspectos que consideravam importantes no estudo dos gráficos da função.

A análise dos textos escritos pelos alunos evidenciou o modo pelo qual o uso do software GeoGebra modificou a sua postura na aula. Tanto quanto estudar funções trigonométricas "no computador", conforme disse a maioria deles, o trabalho em duplas e a escrita sobre matemática foi surpresa para os alunos. Analisando a experiência vivida, registrada em vídeo ou por meio da escrita dos alunos, concluímos que o trabalho com o software favoreceu a investigação gráfica, levando os alunos a construção de hipóteses e a 
argumentação. A escrita da carta foi uma forma deles elegerem informações relevantes ao tema estudado e expor o pensar matemático. Embora sem usar a linguagem rigorosa, a maioria dos alunos foi capaz de expor o que compreendia a partir da manipulação do gráfico das funções estudadas e o modo pelo qual haviam feito variações nesses gráficos. Identificaram com correção o domínio e a imagem das funções e conseguiram compará-las.

De acordo com Cunha (1995, p. 1) "atividades como essa, que proporcionam a investigação nas aulas de matemática, podem promover uma aprendizagem matemática significativa". Ou seja, a exploração dos gráficos de funções trigonométricas colocou os alunos em um ambiente ainda desconhecido por eles: o uso da informática na disciplina de matemática. Porém, o desafio que a eles era apresentado motivou-os à análise. Eles não desistiram; pelo contrário, aceitaram o desafio e se sentiram capazes de compreender matemática. Se entendermos, com Fiorentini e Miorim (1996, p.5), que "[...] ao aluno deve ser dado o direito de aprender. Não um 'aprender' mecânico, repetitivo, de fazer sem saber o que faz e o por que faz [...]", mas um saber que permite ao sujeito expor o sentido que uma exploração fez para si, então podemos dizer que houve um aprender.

Para os bolsistas do PIBID envolvidos na atividade, alunos do curso de Licenciatura em Matemática, também houve um aprender. Aprender que é preciso dar oportunidade ao aluno para que ele possa expressar o seu pensamento.

Desde a elaboração da tarefa até o diálogo com o professor da turma e o orientador da universidade, a matemática se mostrava para os bolsistas de outro modo. Um modo que clamava por sentido: sentido para si e para o outro. Um modo que ia se constituindo no desenrolar das ações. Havia, por parte dos bolsistas, uma compreensão do conteúdo, mas era preciso aprender como ensinar, como permitir ao outro compreender. Essa é uma atitude que precisa ser tomada e cujas consequências precisam ser assumidas. Não se trata de não planejar, mas de ter um fio condutor, um objetivo e uma convicção: a de que é possível aprender pela investigação. Mas qual o sentido desse aprender? Segundo o que compreendemos, e desejamos expressar neste texto, é um aprender para além das fronteiras do conteúdo. Um aprender que se abre em possibilidades de dizer e de fazer. Um aprender matemática permeado pelas opiniões dos alunos, entendidos como sujeitos pensantes, seres humanos que vivem no mundo da cotidianidade que, embora seja impregnada de matemática, não tem características de uma matemática escolar. É aprender a encontrar-se com as possibilidades de, pelas ações que visam ensinar matemática na sala 
de aula, ouvir o aluno, dar possibilidades de ele expressar o que compreende, o que é capaz de analisar, o que está lhe fazendo sentido.

\section{Referências:}

BORBA, M. de C. Softwares e Internet na sala de aula de Matemática. X Encontro Nacional de Educação Matemática. In: Anais ... Salvador, Bahia. 2010. Disponível em http://www.rc.unesp.br/gpimem/downloads/artigos/borba/marceloxenen.PDF. Acesso em 10 de julho de 2017.

CUNHA, M. I. de. Conta-me Agora! as narrativas como alternativas pedagógicas na pesquisa e no ensino. Revista da Faculdade de Educação. São Paulo, v. 23, n. 1-2, jan-dez. 1997. Disponível em http://www.scielo.br/scielo.php?script=sci_arttext\&pid=S010225551997000100010 . Acesso em 08 de maio de 2017.

D'AMBRÓSIO, B.; LOPES, C. E. Insubordinação criativa: um convite à reinvenção do educador matemático. BOLEMA. Boletim de Educação Matemática. Rio Claro (SP), v. 29, n. 51, p. 1-17, abr. 2015. Disponível em http://www.scielo.br/pdf/bolema/v29n51/1980-4415bolema-29-51-0001.pdf. Acesso em 10 de abril de 2017.

FIORENTINI, Dário, MIORIM, Maria A. Uma reflexão sobre o uso de materiais concretos e jogos no ensino da Matemática. Boletim SBEM, São Paulo, v.4, n.7, 1996.

PONTE, J. P. Aprender conceitos e procedimentos matemáticos e aprender a pensar matematicamente. Palestra de Abertura do VI SHIAM. Seminário Nacional de História e Investigação de/em Aulas de Matemática. Caderno de Resumos. Disponível em <https://www.cempem.fe.unicamp.br/pf-cempem/caderno_de_resumo_shiam_2017.pdf >. Acesso em 26 de julho de 2017.

Submissão: 18/08/2017

Aceite: 28/11/2017 